\title{
Current Situation, Trends and Countermeasures for Overseas Education of Universities and Colleges in Yunnan Province in the Context of the "Belt and Road Initiative"
}

\author{
Qian Zeng \\ International Office \\ Yunnan University of Finance and Economics \\ Kunming, P. R. China \\ Edwardzeng@ynufe.edu.cn \\ Jing Wang \\ International Business School \\ Yunnan University of Finance and Economics
}

\author{
Yiyin Jin* \\ School of International Languages and Cultures \\ Yunnan University of Finance and Economics \\ Kunming, P. R. China \\ 358221449@qq.com
}

Kunming, P. R. China

wangjing@ynufe.edu.cn

\begin{abstract}
Overseas education of Chinese universities and colleges has generally experienced three stages: the stage of exploration, the stage of legally running schools, and the stage of rapid development in recent years; the research on this topic by the academia has gradually come into focus. With the overall development being at a leading level in China so far, universities and colleges in Yunnan Province has their regional advantage to run schools abroad. However, according to the SWOT analysis on overseas education of universities and colleges in Yunnan Province, the weakness of it lies in the lack of international curriculum system and faculty, while the threats facing are the monopoly position of developed countries in the education service trade market as well as academic strengths of colleges and universities in coastal areas of China. The most important opportunity for overseas education is the implementation of national public diplomacy strategy and the strategy of regional economic internationalization. To promote overseas education, relevant policies and regulations as well as the education quality assurance mechanism should be further improved by the government. Meanwhile, the construction of school capacity and the strategic research of education output should be strengthened in colleges and universities.
\end{abstract}

Keywords-cross-border education; running educational institutions overseas; internationalization of higher education

\section{INTRODUCTION}

Running schools or programs overseas belongs to the category of "cross-border education" referred in the 2nd International Education Service Trade Forum in November 2003, jointly held by the Organization for Economic Cooperation and Development (OECD) and Ministry of Education of Norway [1]. In more details, it belongs to the third category: the cross-border flow of educational institutions, which means "setting up education and training institutions abroad or carrying out cooperation in education" [2]. According to the Interim Measures Governing Universities and Colleges Engaged in Overseas Education (nullified for new measures) of China, universities and colleges running school overseas refers to "the universities and colleges that establish, independently or jointly with the educational institutions and other social organizations that have the status of legal person and are acknowledged by the government of the country (region) where they are located, educational institutions abroad mainly for recruiting overseas citizens as students, or adopt other forms to engage in educational institution and teaching activities, to engage in diploma education, degree education and non-diploma higher education". Overseas education of China can be traced back to the 1980s, mainly serving as a supplementary form for international student education at that time. Measures Governing Universities and Colleges Engaged in Overseas Education issued by Ministry of Education of the People's Republic of China in 2002 marked that overseas education had become an independent and indispensable part of the higher education system of China [3]. With the improvement of China's international influence in the past decade, the internationalization strength of Chinese universities and colleges has been enhanced and universities and colleges have sought to running schools overseas. By November 2016, 5 overseas education institutions and 98 overseas education programs have been approved by Ministry of Education of the People's Republic of China [4]. Due to its geographical advantage, Yunnan Province ranks top in China so far in overseas education practices, with 15 overseas education programs and institutions (institutions and programs that have been signed and under preparation are included) at present, including one of the 5 overseas educational institutions

*Corresponding author 
approved by the Ministry of Education of the People's Republic of China. Taking Yunnan Province as an example, overseas education institutions and programs as objects of the study (institutions for international promotion of Chinese such as Confucius Institutes and Confucius Classrooms are not included), and on the basis of reviewing the history of overseas education of universities and colleges, this paper, through application of the SWOT theoretical framework, analyzes the advantages, weaknesses, opportunities and challenges faced by Yunnan's universities and colleges in running school overseas and puts forward countermeasures accordingly for further development.

\section{DEVELOPMENT OF OVERSEAS EDUCATION OF UNIVERSITIES AND COLLEGES IN YUNNAN PROVINCE}

The global economic integration provides a powerful driving force for the internationalization of higher education. The internationalization of higher education represented by the "Bologna Process in Europe" has become a trend of global higher education, where overseas education in the category of cross-border education becomes a prominent part and an approach of global education integration. Overseas education of universities and colleges in Yunnan Province has experienced the following three main development stages.

The first stage: the stage of exploration from the end of the twentieth century to 2002. During this period, running schools overseas by universities and colleges was not clearly defined in existing laws and regulations, serving as a supplementary form for international student education and mainly relying on the teaching resources of traditional predominant disciplines and majors. Overseas education of universities and colleges in Yunnan Province was in a preparation stage during the period, with universities and colleges having plans but no results.

The second stage: the stage of legally running schools from 2002 to 2010. This period was marked by the Measures Governing Universities and Colleges Engaged in Overseas Education (hereinafter referred to as "the Measures") first formulated by the Ministry of Education of the People's Republic of China in 2002, which clarified the overseas education policies of "exploring actively, progressing steadily, doing according to their abilities, ensuring quality, managing normatively and running school in accordance with the law", encouraged distinctive, capable and qualified universities and colleges to go abroad to explore setting up joint schools, as well as specified details of limits and procedures for examining and approving authority as well as degree awarding.

Although the Measures were comparatively rough at that time, it enabled overseas education activities to have laws and rules to follow and to go on the track of standardized management. During this period, universities and colleges in Yunnan Province took the first step in running schools overseas. Since 2010, universities and colleges in Yunnan Province have started to enhance the cooperation with ASEAN countries and to gradually export education service to ASEAN countries, including: Kunming University of Science and Technology set up Chinese Culture School in Thailand and carried out postgraduate training programs in Laos, Dali University carried out diploma education programs of Chinese major in Cambodia, as well as Honghe University carried out 4 undergraduate overseas education programs in Vietnam [5]. During this period, overseas education of universities and colleges in Yunnan Province started to export diploma education to other countries, but failed to get rid of discipline limitation of mainly replying on Chinese education.

The third stage: the stage of rapid development since 2011. With the implementation of the National Outline for Medium and Long-term Education Reform and Development (20102020) issued in July 2010, especially the signing of International Memorandum of Carrying out "Belt and Road" Educational Action by the Ministry of Education and the People's Government of Yunnan Province in April 2017, enthusiasm of running schools overseas by universities and colleges in Yunnan Province has been significantly boosted. This period was represented by the establishment of Bangkok Business School of Yunnan University of Finance and Economics in 2014, followed by a batch of Sino-foreign cooperative education institutions and programs such as ChinaThailand Robots and Artificial Intelligence School (Thailand) of Kunming University of Science and Technology as well as China-Myanmar Vocational \& Technical Institute of Yunnan University. During this stage, running schools overseas by universities and colleges in Yunnan Province had two prominent features: firstly, the total number increased steadily; secondly, universities and colleges began to gradually extend to business, science and engineering majors according to their own discipline advantages.

\section{STATUS QUO OF OVERSEAS EDUCATION OF UNIVERSITIES AND COLLEGES IN YUNNAN PROVINCE}

So far, universities and colleges in Yunnan Province have 15 overseas education institutions and programs in total, including 12 institutions and 3 programs. These overseas education institutions and programs feature centralized national and regional distribution, distinctive disciplines and majors, obvious echelons of the universities and colleges, as well as complete coverage of degrees. (See Table 1) 
TABLE I. LIST OF OVERSEAS EdUCATION OF UNIVERSITIES AND COLLEGES IN YUNNAN PROVINCE

\begin{tabular}{|c|c|c|c|c|c|c|c|}
\hline No. & Name & Chinese Uni. & Foreign Uni./Org. & location & Type & Programs & Degree \\
\hline 1 & Bangkok Business School & YUFE & Rangsit University & Thailand & Institute & International business & Bachelor \\
\hline 2 & China-Myanmar Vocational Institute & YNU & Fuqing School & Myanmar & Institute & $\begin{array}{l}\text { Cuisine, mechanical } \\
\text { maintenance }\end{array}$ & Non-Degree \\
\hline 3 & Sino-Thailand Robot \& AI Institute & KUST & $\begin{array}{l}\text { Northern Royal Uni. of Science and } \\
\text { Technology }\end{array}$ & Thailand & Institute & Engineering & Bachelor \\
\hline 4 & Renewable Energy Institute & KUST & Naresuan University & Thailand & Institute & New Energy & Master \\
\hline 5 & KUST-DPU-CIC & KUST & Dhurakij Pundit University & Thailand & Institute & $\begin{array}{l}\text { Int'l Trade, Int'l Finance, } \\
\text { Int'l Chinese }\end{array}$ & Degrees \\
\hline 6 & Souphanouvong Chinese Center & KUST & Souphanouvong University & Laos & Center & Chinese & Non-Degree \\
\hline 7 & Ho Chi Minh Chinese Center & KUST & $\begin{array}{l}\text { HCMC University of Technology and } \\
\text { Education }\end{array}$ & Vietnam & Center & Chinese & Non-Degree \\
\hline 8 & $\begin{array}{l}\text { Chinese Center in Tuy Hoa } \\
\text { Engineering Institute }\end{array}$ & KUST & Tuy Hoa Engineering Institute & Vietnam & Center & Chinese & Non-Degree \\
\hline 9 & $\begin{array}{l}\text { Yunhua vocational technical College, } \\
\text { Myanmar }\end{array}$ & YNNU & Educational Group in Mandalay & Myanmar & Institute & preprimary education & $\begin{array}{l}\text { Associate } \\
\text { Degree }\end{array}$ \\
\hline 10 & $\begin{array}{l}\text { Yunhua vocational technical College, } \\
\text { Cambodia }\end{array}$ & YNNU & $\begin{array}{l}\text { Chinese language school in Mae Sai, } \\
\text { Chiang Rai }\end{array}$ & Thailand & Institute & Chinese & $\begin{array}{l}\text { Associate } \\
\text { Degree }\end{array}$ \\
\hline 11 & RUPP-DHY Chinese Center & DU & Royal University of Phnom Penh & Cambodia & Institute & Chinese Language & $\begin{array}{l}\text { Bachelor Non- } \\
\text { degree }\end{array}$ \\
\hline 12 & YJC- Bang Pakong Campus & $\begin{array}{l}\text { Yunnan Jiaotong } \\
\text { College }\end{array}$ & $\begin{array}{l}\text { Bang Pakong Industrial \& Community } \\
\text { Education College }\end{array}$ & Thailand & Institute & Rail Transit, Logistics & $\begin{array}{l}\text { Associate } \\
\text { Degree }\end{array}$ \\
\hline 13 & HU BA program in Vietnam & $\mathrm{HU}$ & (Thai Nguyen University & Vietnam & Program & Int`l Economy and Trade & Bachelor \\
\hline 14 & KUST postgraduate Program, Laos & KUST & National University Of Laos & Laos & Program & Int'l Finance & Master、 $\mathrm{PhD}$ \\
\hline 15 & Int'l Chinese Master Program & YNU & Fuqing School & Myanmar & Program & Int'l Chinese & Master \\
\hline
\end{tabular}

Regional and national distribution. Due to the close economic relation and similar social culture between China and ASEAN countries as well as their obvious geographical advantages, ASEAN countries have become the favored destinations for overseas education by universities and colleges in Yunnan Province. Among them, Thailand ranks the top with 6, accounting for 40\%; followed by Vietnam with $3(20 \%)$, Myanmar with $3(20 \%)$, Laos with 2 (13\%) and Cambodia with $1(7 \%)$.

Discipline and major distribution. Among the overseas schools run by universities and colleges in Yunnan Province, degree education mainly covers 5 literature majors, 5 economy and management majors, and 3 engineering majors. Literature majors mainly focus on the traditional Chinese major that was opened in the early overseas education of most universities and colleges. But with the improvement of the experience in overseas education of universities and colleges and further knowledge of demand of targeted countries, universities and colleges tend to set up tailor-made majors for targeted market, combined with their own disciplinary advantages. Therefore, in recent years, disciplines and majors such as economy, management, finance and artificial intelligence have become popular in overseas education of universities and colleges in Yunnan Province.

Constitution of universities and colleges and structure of academic degrees. There are 1 "Double First-Class" university (first-class university with first-class disciplines), 23 ordinary colleges and universities, and 13 technical colleges in Yunnan Province. Among them, 7 universities and colleges have participated in the overseas education, including 1 "Double First-Class" university, 15 ordinary colleges and universities, and 1 technical college. Kunming University of Science and Technology has set up 7 institutions and programs in total, ranking the top. The above institutions and programs of overseas education include both non-diploma education and diploma education. Among them, diploma education covers junior college, undergraduate, master and doctor education, forming a relatively integrated academic degree system of overseas education.

\section{SWOT ANALYSIS ON OVERSEAS EDUCATION OF UNIVERSITIES AND COLLEGES IN YUNNAN PROVINCE}

Initially developed by an American scholar named Albert Humphrey, SWOT Analysis is a common strategy analysis tool. A SWOT Analysis will help to diagnose and provide a clear picture of the overseas education of Yunnan Province. (See Figure 1)

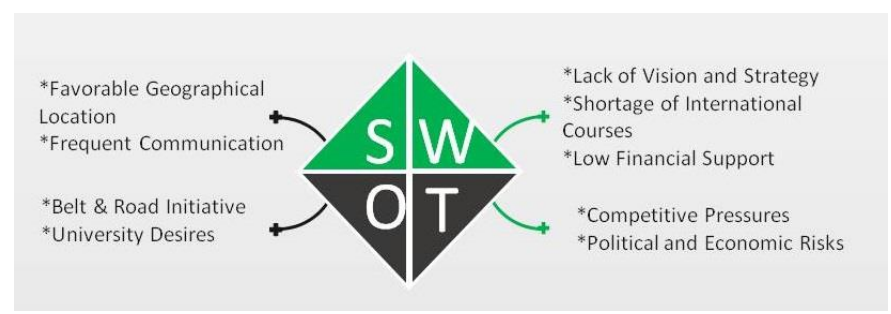

Fig. 1. SWOT Analysis of Overseas Education of Yunnan Province 


\section{A. Advantages of Overseas Education of Universities and Colleges in Yunnan Province}

Firstly, Yunnan Province boasts the superiority of geographical location. Situated in the junction of China Economic Circle, Southeast Asia Economic Circle and South Asia Economic Circle, Yunnan is an international passage linking China with South Asia and Southeast Asia, enjoying the unique geographical advantages of facing Southeast Asia, South Asia and West Asia, adjoining the Pacific Ocean and the Indian Ocean, and possession of favorable traffic conditions. Therefore, as the "leading area" that bridges Southeast Asia and South Asia in fields like politics, economy and culture, Yunnan Province plays an important role as the window. In recent years, by vigorously deepening the exchanges and cooperation with countries in Southeast Asia, South Asia and the Great Mekong Subregion (GMS), Yunnan Province gradually embodies its prominent pivotal role in the "Belt and Road Initiative".

Secondly, Yunnan Province boasts the superiority in communication. As Yunnan Province adjoins countries in Southeast Asia and South Asia, it has tied close relationship with those countries on exchanges of people, languages and logistics since ancient times. Among 26 ethnic groups in Yunnan Province, 17 of them are cross-border groups [6]. Due to common historical origins, languages and cultural conventions, as well as the long-term contact and cultural fusion among ethnic groups, particularly the increasingly intimate economic and trade exchanges facilitated by ChinaASEAN Free Trade Area (CAFTA) since 2010, Yunnan has been endowed with distinct advantages on cultural and educational exchanges when conducting higher education communication with countries of Southeast Asia and South Asia.

\section{B. Disadvantages of Overseas Education of Universities and Colleges in Yunnan Province}

Firstly, Yunnan Province lacks the strategic consciousness of running schools overseas. Resulting from the high threshold, heavy investment, great risk and unpredictable return, universities and colleges are more willing to devote energy to the still thriving domestic and provincial education markets. Thus, universities and colleges lack the awareness, motivation and mechanism to run institutions abroad and actively participate in the international trade.

Secondly, Yunnan province is weak in English course system and faculty resources. In most universities and colleges, a relatively complete discipline system taught in English has not been formed, causing fragmentization of major courses. Meanwhile, the international faculty building in universities and colleges has greatly lagged behind what is required by overseas education. The ratio that university and college teachers teach in English registers low, even worse for that of eligible teachers willing to teach abroad.

Finally, Yunnan Province lacks a multi-input mechanism. As current fiscal policy of China allows no public universities and colleges to invest in overseas educational institutions, and the enrollment scale has been enlarged, universities and colleges actually lack fund for running schools overseas.
However, a regular phenomenon is that the output country suffers from weak economic foundation and seriously inadequate educational investment. Taking those conditions into account, it is necessary for government to render certain financial support and preferential policies to overseas education as those provided for Confucius Institutes, so that universities and colleges can raise and attract social funds to support the overseas education.

\section{Opportunities for Overseas Education of Universities and Colleges in Yunnan Province}

Firstly, China offers policy opportunities. "Belt and Road Initiative" proposed in 2012 provided Yunnan with favorable opportunities to further exchange and cooperate with Southeast Asia and South Asia on education, as well as to blazed vast development space for universities and colleges to enhance the cooperation and exchange with neighboring national counterparts and scientific research institutions, so that Yunnan has confirmed its status of "Radiation Center of Higher Education".

Secondly, universities and colleges in Yunnan Province strengthened the intention for internationalized. Developing the overseas education not only assists universities and colleges in blending into the integration process of higher education, but also boosts the enhancement of connotation and quality construction of higher education in Yunnan Province. That is to say, while expanding the enrollment sources, optimizing the structure, promoting the internationalization of current courses and building the international images of universities and colleges, the cooperative universities and colleges in input country shall be built into the stable enrollment base to generate direct economic returns for universities and colleges.

\section{Challenges of Overseas Education of Universities and Colleges in Yunnan Province}

Firstly, domestic and overseas universities and colleges face with intense competitive pressure. On the one hand, domestic "Double First-Class" universities, such as Peking University, Tsinghua University, Fudan University and Xiamen University, have accelerated to develop international market for students source, with Xiamen University Malaysia Campus as one of the best examples. In the meantime, universities and colleges in neighboring provinces, such as Sichuan University, Chongqing University, Guizhou University and Guangxi University have greatly blunted the location advantage of universities and colleges in Yunnan to run overseas educational institutions. On the other hand, universities and colleges in developed countries on higher education involving Europe, USA, Japan, Australia and Korea are strong competitors. For instance, the UK higher education institutions have established projects or branch schools globally except for 15 countries by 2016. In addition, the total number of cross-border students in $2014 / 2015$ increased by $13 \%$ compared with that of $2013 / 2014$ [7].

Secondly, overseas politics and economy face with unstable policy risks. Although some countries have built win-win relationship on educational cooperation with China, they still suffer from unstable domestic political situation. Any "sign of disturbance or trouble" on regime change and policy alteration 
will pose potential financial and personnel hazards for Chinese universities and colleges running schools overseas. Due to the reason that some countries have oriented cross-border educational institutions as overseas-funded enterprises, the overseas educational institutions and projects of output countries have been deprived of privilege of preferential policies concerning business tax, income tax and import tax that enjoyed by non-profit organizations and projects. Thus, facing a higher cost for running overseas institutions, universities and colleges are bound to undertake greater operational risk.

\section{SUGGESTIONS CONCERNING OVERSEAS EDUCATION OF UNIVERSITIES AND COLLEGES IN YUNNAN PROVINCE}

Firstly, relevant policies and regulations shall be improved to render support to overseas education. By incorporating overseas education into the master planning of reform and development of higher education, four major strategic emphases, namely, capacity building, quality assurance, education service trade as well as cultural and educational exchange shall be prioritized, so as to formulate the development strategy of overseas education. Secondly, the newly revised Management Method on Overseas Education of Universities and Colleges (hereinafter referred to as "Method") shall be released in a quick manner. As both the domestic and international higher education markets have witnessed tremendous changes, "going global" strategy has specifically embodied the soft power output of China. The deficiencies in relevant active laws and regulations are seriously impeding universities and colleges in running educational institutions overseas. The revised Method shall further clarify and detail various aspects involving definition, boundary, category, approval authority and procedure and degree awarding of overseas education, so as to standardize actions in running educational institutions overseas. Thirdly, policy and financial support shall be enhanced. In consideration of the significant role of overseas education in the national public diplomatic strategy and education internationalization, the policy support to overseas educational institutions and projects shall be fully accounted, when implementing China-aid foreign projects and governmental scholarship programs for overseas students.

Secondly, quality assurance mechanism shall be improved to regulate overseas education. By referring to the advanced experience of powerful education output countries like Australia and the UK, it is urgent to establish the cross-border organizations for education quality assurance, and build the quality assurance mechanism among universities and colleges, government and quality assurance organizations, in which, specific duties have been clarified, the three bodies have checked and balanced each other, and benign interaction have been circulated. Under this mechanism, the quality assurance system at the national level plays the key role. Hence, it is imperative to formulate academic quality and assessment criteria concerning overseas cooperative education, and implement the on-site quality review mechanism to domestic universities and colleges, so as to value the quality control of overseas education as measure for building great-nation image.

Thirdly, disciplinary advantages and characteristics, as well as the overseas educational resources shall be integrated. In accordance with the provincial strategic orientation on internationalization and individual development goals, universities and colleges in Yunnan Province shall energetically implement the overseas education in a stable manner. Among schools, the disciplinary professional advantages shall be integrated to avoid repeated construction and completely eradicate cutthroat competition. Meanwhile, the output pattern shall be gradually shifted from the traditional resource-oriented (taking individual disciplinary advantages as the priority) to the demand-oriented one (taking the demands of emerging industry, pillar industry and industrial restructuring in input countries as priorities), and the disciplines and majors in overseas education shall be arranged in a more active and scientific manner, so as to cater for the demand of international higher education market, maintaining the competitiveness and sustainability of overseas education conducted by universities and colleges of Yunnan Province.

Finally, the theoretical and practical researches shall be reinforced to probe into the new approaches to overseas education. Firstly, researches on society, history, culture, crossborder higher education market, legal framework of crossborder education, educational governance structure and operation mode of educational authorities in target country shall be strengthened. Secondly, risks in overseas education shall be correctly comprehended. Those mainly include financial risk, non-determinacy brought by cultural and legal differences, policy risk and non-replicability of teaching system. Thirdly, by adopting various methods involving positively researching on the fund-raising approach for overseas education to vie for multi-input, taxes deduction and exemption, as well as implementation of special subsidy, universities and colleges shall seek for the financial support of social forces, particularly that of overseas-funding enterprises, and support of strategic investors, banks and government of target country.

\section{ACKNOWLEDGEMENT}

First of all, I would like to extend my gratitude to my coauthors for their dedicated work and support from the very beginning to the completion of this paper.

I also would like to thank Yunnan Provincial Department of Education, which supported this research by granting a research projects to me to carry out the relevant research.

Lastly, I offer my regards to all of those who supported us in any respect during the completion of this work.

\section{REFERENCE}

[1] OECD. Quality and recognition in higher education-The cross-border challenge[R] .2004

[2] OECD. Cross border education: An overview, OECD/Norway forum on trade in educational services: Managing the internationalization of post-secondary education [R]. 2003

[3] L. Guo. "Status quo, motivation, and future development of running schools overseas by universities and colleges in China", 2012 11(8):92 96. [A]. Science and Engineering Research Center. Proceedings of 2017 4th International Conference on Education Reform and Modern Management(ERMM 2017)[C].Science and Engineering Research Center:,2017:5 
[4] Guangming Daily (the $14^{\text {th }}$ Edition on 29 November, 2016)

[5] Y. Li, and LG. Meng, "Analysis on running schools overseas by the newly-established university---Taking Honghe university for example" [J]. Journal of Dali University, Science Edition, 2012, 11(8):92-96.

[6] S. Song, "Analysis and reflection on status of education of students abroad in agricultural universities and colleges: Empirical analysis based on statistics collected in 2003-2012" [J]: Higher Agricultural Education, 2014 (4): 58.

[7] UK Higher Education International Unit, "The scale and scope of UK higher education transnational education 2016”,2016:6 